\title{
Numerical Evaluation of a Light-Gas Gun Facility for Impact Test
}

\author{
C. Rahner, ${ }^{1}$ H. A. Al-Qureshi, ${ }^{1}$ D. Stainer, ${ }^{2}$ D. Hotza, ${ }^{1}$ and M. C. Fredel ${ }^{1}$ \\ ${ }^{1}$ Departments of Mechanical Engineering (EMC) and Chemical Engineering (EQA), \\ Laboratory of Ceramic and Composite Materials (CERMAT), Federal University of Santa Catarina (UFSC), \\ 88040-900 Florianópolis, SC, Brazil \\ ${ }^{2}$ CMC Tecnologia, Avenida Roberto Galli 1220, 88045-000 Cocal do Sul, SC, Brazil
}

Correspondence should be addressed to D. Hotza; dhotza@gmail.com

Received 19 March 2014; Revised 27 June 2014; Accepted 27 June 2014; Published 19 August 2014

Academic Editor: Dimitrios E. Manolakos

Copyright (C) 2014 C. Rahner et al. This is an open access article distributed under the Creative Commons Attribution License, which permits unrestricted use, distribution, and reproduction in any medium, provided the original work is properly cited.

Experimental tests which match the application conditions might be used to properly evaluate materials for specific applications. High velocity impacts can be simulated using light-gas gun facilities, which come in different types and complexities. In this work different setups for a one-stage light-gas gun facility have been numerically analyzed in order to evaluate their suitability for testing materials and composites used as armor protection. A maximal barrel length of $6 \mathrm{~m}$ and a maximal reservoir pressure of a standard industrial gas bottle $(20 \mathrm{MPa})$ were chosen as limitations. The numerical predictions show that it is not possible to accelerate the projectile directly to the desired velocity with nitrogen, helium, or hydrogen as propellant gas. When using a sabot corresponding to a higher bore diameter, the necessary velocity is achievable with helium and hydrogen gases.

\section{Introduction}

The knowledge of material properties involved in impact situations is critical in different technological areas in order to guarantee safe operations. In order to evaluate the impact damage on materials and systems, specific equipment tools are needed. An experimental light-gas gun should operate in a similar way to a conventional gun with powder. The main difference is constituted by the means of achieving the necessary pressure to accelerate the projectile. As a conventional gun utilizes the combustion of a propellant charge, a light-gas gun operates with a compressed gas reservoir [1].

Gas-gun facilities can be applied to simulate a range of different situations, varying with the characteristics of the gun itself. Obviously, since their system was derived from conventional guns, light-gas guns can be used to simulate ballistic impacts of various sizes and energies. Common types of lightgas guns are the one-stage light-gas gun, two-stage light gas gun, and the shock tunnel or shock tube. One-stage lightgas guns are rather simple in design, being just one pressure reservoir that accelerates a projectile through a barrel onto the target. The more sophisticated two-stage gun is based on the one-stage gun, but it furthermore has a second stage of compression that increases the pressure in the pressure tank, for example, by combustion, by heating, or by free piston compression in an extra tube mounted before the barrel [2]. Shock tunnels or shock tubes differ as they do not fire projectiles but only produce a gas blast wave on a target [3].

Light-gas guns are employed to test materials and composites for their possible application as armors, for both persons and vehicles. On a smaller scale, it is possible to simulate the impact of a stone on a driving vehicle on accelerated velocities or of ice rocks on a travelling aircraft. Another possible application is to test spacecraft components or materials for their suitability to be used for such a task. There is an ever-growing threat to spacecraft in the form of the impact of micrometeoroids and man-made orbital debris. It is estimated that $200 \mathrm{~kg}$ of meteoroid mass exists in a distance of $2000 \mathrm{~km}$ of the Earth's surface; the majority of it is $0.1-\mathrm{mm}$ micrometeoroids. Additionally, within the same distance around the Earth, there is $300 \mathrm{~kg}$ of orbital debris with diameters of less than $1 \mathrm{~mm}$. Those particles are small 


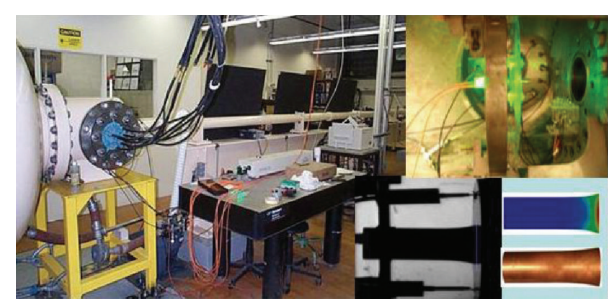

Figure 1: High-strain-rate gas-gun laboratory at Georgia Tech [8].

but they can be found travelling with 10 to $20 \mathrm{~km} / \mathrm{s}$ relative velocity to an orbiting spacecraft [4]. To protect spacecraft and astronauts against the results of an impact at these extremely high velocities, it is necessary to test and model shielding systems against those dangers [5].

Extremely high velocity threats in a laboratory can be simulated using a two-stage light-gas gun system [7]. One example for a powerful two-stage gun is displayed in Figure 1. This facility accelerates projectiles with $80 \mathrm{~mm}$ in diameter to a maximum velocity of $1.2 \mathrm{~km} / \mathrm{s}$ using an $8 \mathrm{~m}$ barrel and a $28.5 \mathrm{dm}^{3}$ gas chamber [8]. Light-gas guns remain the only equipment able to accelerate projectiles of different shapes and masses to a muzzle velocity of up to $11 \mathrm{~km} / \mathrm{s}$ [9].

It is also possible to conduct tests with light-gas gun equipment to replicate and direct blast waves at test sample or a sensor in a shock tunnel. This allows simulating explosions and their effects. It may also be used to examine aerodynamic flow under a wide range of temperatures and pressures and to study compressible flow phenomena and gas phase combustion reactions. In a more recent approach, biological specimens have been exposed to shock tubes in order to study how they are affected by blast waves $[10,11]$. The shock tunnel is shown in Figure 2 [12]. It is used, for instance, to simulate the reentry of a spacecraft into the atmosphere.

Alternative ways to increase the muzzle velocity are applying a higher pressure in the gas reservoir, increasing the barrel length, or heating the driving gas, for example, by combustion, arc heating, or detonation [13]. Nevertheless, there remain limitations to the achievable projectile velocities, as the physical properties of the propellant gas, the engineering properties of the facility to withstand the pressure and temperature, and the properties of the projectile itself not to get destroyed by the acceleration force or the base pressure. This is a particular feature for sabot systems, using a lightweight carrier structure for the projectile in order to increase the diameter without adding too much mass, which is somewhat problematic. To overcome those problems there are further approaches, for example, to build multistaged facilities such as Kondo et al's three-stage light-gas gun [14].

As shown in the literature $[15,16]$, different impact velocities will lead to different damage responses, even if the kinetic energy of the impacting bodies is equal. Furthermore, when testing materials for ballistic protection applications, the mechanics to defeat the threat involves destroying partially the projectile [17-19].

In this context, the aim of this work is to evaluate the possibilities and limitations of constructing a simple one-stage

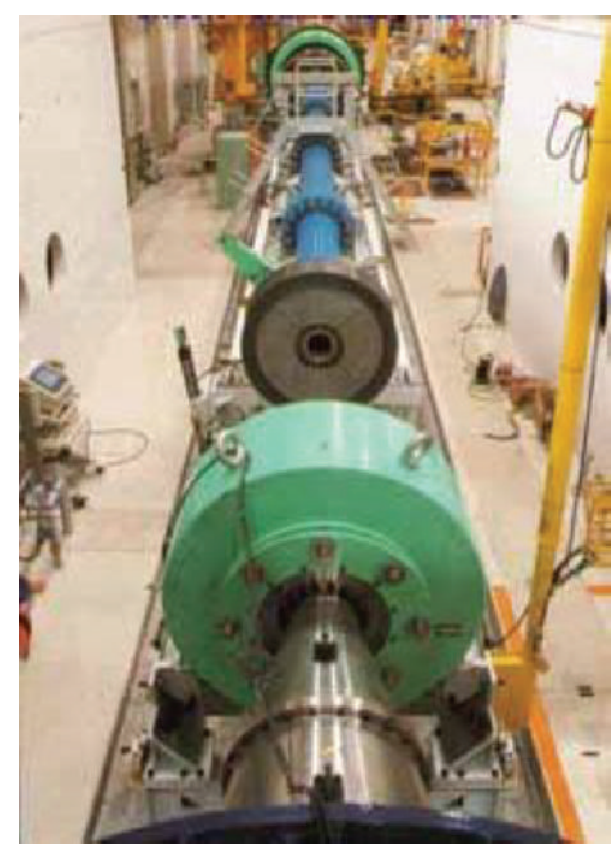

FIGURE 2: Shock-wind tunnel at Mitsubishi Heavy Industries [12].

light-gas gun to test materials for impact resistance. For this, the achievable muzzle velocities with different driving gases, pressure reservoirs, and barrel lengths will be calculated and analyzed. A light-gas gun facility for impact test must be customized for a certain application and may imply high construction and maintaining costs. Thus, the main scope of this work is to provide a first approach to design a system utilizing a $7.62 \mathrm{~mm}$ projectile with a mass of $9.6 \mathrm{~g}$ in order to select the best conditions for setting up an experimental system to be constructed in a next step.

\section{Theoretical Background}

The objective of using a light-gas gun facility is to accelerate a projectile to a desired speed, that is, the muzzle velocity. The acceleration $\dot{v}$ that is produced on the projectile is determined by its mass $m$, the driving gas pressure $P$, and the crosssectional area as displayed in the following equation:

$$
\dot{v}=\frac{P \cdot A}{m} .
$$

Siegel [20] showed that a realistic estimate of the muzzle velocity can be obtained by assuming that the gas reservoir is an infinitely long tube with the same diameter as the barrel thus neglecting reflection and refraction waves in the gas reservoir. In that way the propelling pressure can be related to the projectile velocity $v$ by the following equation:

$$
P=P_{0}\left[1-\frac{(\gamma-1) v}{2 a_{0}}\right]^{2 \gamma /(\gamma-1)},
$$

where $P_{0}$ is the initial pressure; $\gamma$ is the ratio of the specific heat capacities $C_{P} / C_{V}$ at constant pressure and constant 
volume, respectively; and $a_{0}$ is the speed of sound in the driving gas.

Reducing the molecular mass of the propelling gas can increase projectile muzzle velocity. The reason for this is that the gas has to be accelerated as well as the projectile. Therefore, a reduction of the molecular mass results in an increase of the speed of sound and a higher muzzle velocity is achieved. This is because the gas itself has to be accelerated in the same manner as it would be excited by a sound wave. The higher the molecular mass of the gas, the lower the speed of sound and the lower the achievable muzzle velocity. Another factor that has to be taken into account in order to estimate the muzzle velocity is the pressure that is built up in front of the projectile by the atmosphere. This pressure can be described by the following equation [20]:

$$
\begin{aligned}
\frac{P_{t}}{P_{1}} \approx 1 & +\left(\frac{v}{a_{1}}\right)^{2} \frac{\gamma_{1}\left(\gamma_{1}+1\right)}{4} \\
& +\frac{\gamma_{1} v}{a_{1}}\left[1+\left(\frac{\gamma_{1}+1}{4}\right)^{2}\left(\frac{v}{a_{1}}\right)^{2}\right]^{1 / 2},
\end{aligned}
$$

where $P_{t}$ is the pressure that builds up in front of the projectile; $P_{1}$ is the initial pressure in front of the projectile, that is, usually the atmospheric pressure; $\gamma_{1}$ is the ratio of the specific heat capacities of the gas in the barrel and the target chamber, usually air; and $a_{1}$ is its speed of sound.

Furthermore, another factor reducing the acceleration of the projectile is the loss of pressure due to the increase of pressured volume; since the projectile travels down the barrel, the driving gas gets distributed over more space. This relation can be expressed by

$$
P=P_{0} \frac{V}{V_{0}},
$$

where $V$ is the volume of the pressurized area at any given moment and $V_{0}$ is the initial volume of the pressure reservoir.

Inserting (2), (3), and (4) in (1) it is possible to calculate the projectile velocity and displacement by iteration in short intervals [20-22].

\section{Experimental Design}

A simple gas-pressure driven one-stage light-gas gun facility consists basically of a barrel, a gas reservoir as driving force, a chamber to place the projectile, and a mechanism to control the release such as a valve, as shown in Figure 3. Besides the gun itself, it is necessary to set up a suitable target box around the sample, which is constituted by armored walls strong enough to contain the projectile and possible shattered pieces from the impact. The velocity and energy of the projectile depend on the applied pressure as well as the properties of the driving gas, the mass and size of the projectile, the length of the barrel, and the size of the reservoir.

Depending on the barrel length, it might be built by joining several segments together. As release mechanisms different systems can be employed. It is possible to use a magnetic valve as well as a diaphragm, for example, a thin

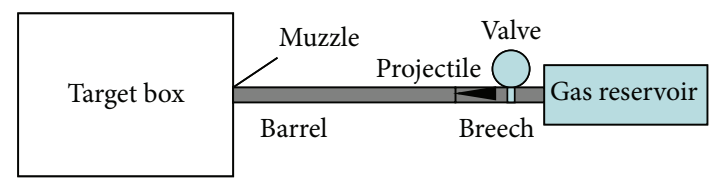

Figure 3: Schematic drawing of a simple one-stage light-gas gun.

TABLE 1: Mass, velocity, and kinetic energy of NIJ test projectiles [6].

\begin{tabular}{llccc}
\hline Type & Test caliber & $\begin{array}{c}\text { Mass } \\
{[\mathrm{g}]}\end{array}$ & $\begin{array}{c}\text { Velocity } \\
{[\mathrm{m} / \mathrm{s}]}\end{array}$ & Energy [J] \\
\hline \multirow{2}{*}{ Type IIA } & 9 mm FMJ RN & 8 & 373 & 556.516 \\
& .40 S\&W FMJ & 11.7 & 352 & 724.838 \\
\hline \multirow{2}{*}{ Type II } & 9 mm FMJ RN & 8 & 398 & 633.616 \\
& .357 magnum JSP & 10.2 & 436 & 969.490 \\
\hline \multirow{2}{*}{ Type IIIA } & .357 SIG FMJ FN & 8.1 & 448 & 812.851 \\
& .44 magnum SJHP & 15.6 & 436 & 1482.749 \\
\hline Type III & 7.62 mm FMJ (M80) & 9.6 & 847 & 3443.563 \\
\hline Type IV & .30 AP (M2 AP) & 10.8 & 878 & 4162.774 \\
\hline
\end{tabular}

copper foil with a thickness that causes the foil to break as the desired pressure is achieved [23].

The gas reservoir either can be a built pressure tank that is being filled with a gas bottle or by a compressor or can be directly the gas bottle itself. Obviously, in latter case the gas bottle should not be bigger than necessary to avoid increased gas usage. Sensors and cameras to record experimental data are to be placed inside the target box as well [24].

Ballistic threats are categorized by different organizations in different levels depending on the utilized firearm and the type of ammunition. The most common categorization is by the United States Department of Justice's National Institute of Justice (NIJ). Table 1 shows the physical data for the projectiles for each level of protection that are used at the test of new protection materials. A full metal jacket (FMJ) is a bullet consisting of a soft core encased in a shell of harder metal. This type exists with different shaped projectiles, for example, round-nosed (RN) and flat-nosed (FN). A jacketed soft-point bullet (JSP) is a lead expanding bullet with a jacket that is left open at the tip, exposing some of the lead inside, and is thus an example of a semijacketed round. A semijacketed hollowpoint bullet (SJHP) is an expanding bullet as well that has a pit or hollowed out shape in its tip to expand upon entering a target in order to decrease penetration and disrupt more tissue as it travels through the target. The materials of the projectiles of threat levels IIA, II, and IIIA are lead as core and a copper alloy of approximately $90 \%$ copper and $10 \%$ zinc as coating; threat level III uses steel as coating. The level IV projectile is a special military armor-piercing round with a copper alloy coating and a steel penetrator core [6].

\section{Results and Discussion}

From the equations presented in Section 2, the possible accelerations and muzzle velocities have been calculated for a one-stage light-gas gun facility considering the specifications 
TABLE 2: Achievable muzzle velocities of projectile according to level III threat $(9.62 \mathrm{~mm}, 9.6 \mathrm{~g})$.

\begin{tabular}{lcccccc}
\hline Gas & $V_{\max }(\mathrm{m} / \mathrm{s})$ & Barrel length $[\mathrm{m}]$ & $V_{3 \mathrm{~m}}[\mathrm{~m} / \mathrm{s}]$ & $V_{6 \mathrm{~m}}[\mathrm{~m} / \mathrm{s}]$ & Pressure $\left[\mathrm{N} / \mathrm{mm}^{2}\right]$ & Reservoir $\left[\mathrm{cm}^{3}\right]$ \\
\hline Nitrogen & 527.99 & 29.88 & 378.51 & 442.19 & 20.00 & 1000.00 \\
Helium & 849.71 & 40.52 & 511.96 & 631.83 & 20.00 & 1000.00 \\
Hydrogen & 1054.78 & 46.74 & 571.28 & 725.14 & 20.00 & 1000.00 \\
\hline
\end{tabular}

TABLE 3: Achievable muzzle velocities (of projectile according to level III threat $(9.62 \mathrm{~mm}, 9.6 \mathrm{~g})$.

\begin{tabular}{|c|c|c|c|c|c|c|}
\hline Gas & $V_{\max }(\mathrm{m} / \mathrm{s})$ & Barrel length [m] & $V_{3 \mathrm{~m}}[\mathrm{~m} / \mathrm{s}]$ & $V_{6 \mathrm{~m}}[\mathrm{~m} / \mathrm{s}]$ & Pressure $\left[\mathrm{N} / \mathrm{mm}^{2}\right]$ & Reservoir $\left[\mathrm{cm}^{3}\right]$ \\
\hline Nitrogen & 564.22 & 39.22 & 382.31 & 450.60 & 20.00 & 2500.00 \\
\hline Helium & 934.14 & 52.79 & 517.89 & 646.69 & 20.00 & 2500.00 \\
\hline Hydrogen & 1187.90 & 61.34 & 578.38 & 744.20 & 20.00 & 2500.00 \\
\hline Nitrogen & 584.19 & 47.72 & 384.07 & 453.41 & 20.00 & 5000.00 \\
\hline Helium & 982.84 & 64.08 & 521.02 & 653.54 & 20.00 & 5000.00 \\
\hline Hydrogen & 1268.56 & 74.78 & 582.33 & 750.10 & 20.00 & 5000.00 \\
\hline
\end{tabular}

on projectiles for level III threats (i.e., a FMJ projectile with $9.6 \mathrm{~g}$ in mass and $7.62 \mathrm{~mm}$ in diameter). Moreover, the maximum available pressure for the gas reservoir has been fixed as $20 \mathrm{MPa}$, which is the pressure of standard industrial gas bottles. The obtained results are presented and discussed below.

Table 2 shows different possible setups with different barrel lengths, diameters, and driving gases. The reservoir size was set as 1 liter. It is easy to see that hydrogen-driven projectiles achieve higher velocities than nitrogen- or heliumdriven ones. The reason for this lies in the different speeds of sound of the gases, as explained before. $V_{\max }$ is the maximum velocity achievable for the respective setup, which is reached at the given barrel length. If a longer barrel would be applied, then the counter pressure in front of the projectile would result in a higher deceleration than the remaining pressure in the reservoir and the barrel, so that the muzzle velocity would actually be lower for even longer barrels.

The maximal achievable velocities using helium and hydrogen would be sufficient for level III and, in the case of hydrogen, even for level IV tests. However, barrel lengths of over $40 \mathrm{~m}$ are far from being reasonable. Apart from the space, such facility would require constructing a barrel without leakage, completely plane and leveled, what would render such a design unfit to serve the desired motivation of constructing a simple assembly. The muzzle velocities for reasonable barrel lengths of $3 \mathrm{~m}$ and $6 \mathrm{~m}$ are shown in Table 2 as $V_{3 \mathrm{~m}}$ and $V_{6 \mathrm{~m}}$ values. Therefore, even with using hydrogen as propellant gas and a $6 \mathrm{~m}$ long barrel it is not possible to achieve the desired muzzle velocity of $847 \mathrm{~m} / \mathrm{s}$ for level III testing.

Table 3 shows the results for larger gas reservoirs. Although the maximal speeds are increased, they come with even longer barrels. The achievable muzzle velocities with $3 \mathrm{~m}$ and $6 \mathrm{~m}$ barrels do not differ highly from those with big reservoirs. The larger reservoir results in a slower decrease in acceleration pressure and therefore acceleration force is higher than the counter pressure for a longer time. In this way, the muzzle velocity increases with a $3 \mathrm{~m}$ barrel and nitrogen from $378.51 \mathrm{~m} / \mathrm{s}\left(100 \%\right.$ at $\left.1000 \mathrm{~cm}^{3}\right)$ to $382.31 \mathrm{~m} / \mathrm{s}(101 \%$ at $\left.2500 \mathrm{~cm}^{3}\right)$ to $384.07 \mathrm{~m} / \mathrm{s}\left(101.5 \%\right.$ at $\left.5000 \mathrm{~cm}^{3}\right)$. The increase is slightly higher with a $6 \mathrm{~m}$ long barrel, $102 \%$ with $2500 \mathrm{~cm}^{3}$ and $102.5 \%$ with $5000 \mathrm{~cm}^{3}$.

Based on these calculations, there are three options to achieve the desired muzzle velocities. The first option is to change the design to a two-stage light-gas gun facility. A second stage would increase the pressure in the gas reservoir further and therefore allow higher muzzle velocities. Another way would be to directly use higher pressures. In that case a compressor would have to be employed as a part of the facility since standard industry gas cylinders do not supply higher pressures. The third option would be to employ a sabot as a carrier of the projectile, thus increasing the diameter of the accelerated object without adding significantly mass, as Børvik et al. [25] and Grosch and Riegel [7] did. In that case, assuming a sabot mass of $5 \mathrm{~g}$ and $10 \mathrm{~g}$ to increase the bore diameter of the facility to $40 \mathrm{~mm}$, the calculations are shown in Table 4 . In this case, the performance will depend majorly on the sabot mass. In both cases, only with hydrogen as driving gas it is possible to achieve speeds for level III tests.

Due to the increase of the bore diameter, the reservoir of $1000 \mathrm{~cm}^{3}$ is rather small, since the absolute volume of the area under pressure increases much faster with every travelled distance unit.

Table 4 shows an increase to $108 \%, 112 \%$, and $115 \%$ for nitrogen, helium, and hydrogen, respectively, considering a $5 \mathrm{~g}$ sabot, and $109 \%, 113 \%$, and $116 \%$ with a $10 \mathrm{~g}$ sabot and a reservoir of $2500 \mathrm{~cm}^{3}$. Furthermore, the optimal barrel length to achieve the maximal muzzle velocity has increased. With such a configuration it is possible to achieve the velocity for level III tests of $847 \mathrm{~m} / \mathrm{s}$ using helium or hydrogen and a sabot of either 5 or $10 \mathrm{~g}$.

Still, it is not possible to determine if the chosen value of $40 \mathrm{~mm}$ for the sabot diameter is optimal. Figure 4 and Table 5 show the development of the velocities with different sabot diameters, the sabot mass being fixed at $10 \mathrm{~g}$ in addition to the $9.6 \mathrm{~g}$ of the projectile. As can be seen, the sabots of $35 \mathrm{~mm}$ and $30 \mathrm{~mm}$ in diameter seem to perform better when considering nitrogen as propellant gas. However, with the other two driving gases the $40 \mathrm{~mm}$ sabot still achieves higher muzzle velocities with a $3 \mathrm{~m}$ or less barrel length. 
TABLE 4: Achievable muzzle velocities of projectile according to level III threat ( $40 \mathrm{~mm}, 14.6$, and $19.6 \mathrm{~g})$ with sabots (5 to $10 \mathrm{~g})$.

\begin{tabular}{|c|c|c|c|c|c|c|}
\hline Gas & $V_{\max }(\mathrm{m} / \mathrm{s})$ & Barrel length $[\mathrm{m}]$ & $V_{3 \mathrm{~m}}[\mathrm{~m} / \mathrm{s}]$ & $V_{6 \mathrm{~m}}[\mathrm{~m} / \mathrm{s}]$ & Pressure $\left[\mathrm{N} / \mathrm{mm}^{2}\right]$ & Reservoir $\left[\mathrm{cm}^{3}\right]$ \\
\hline \multicolumn{7}{|c|}{ Projectile according to level III threat with $5 \mathrm{~g}$ sabot ( $40 \mathrm{~mm}$ diameter; $14.6 \mathrm{~g}$ weight) } \\
\hline Nitrogen & 510.61 & 1.40 & - & - & 20.00 & 1000.00 \\
\hline Helium & 807.61 & 2.00 & - & - & 20.00 & 1000.00 \\
\hline Hydrogen & 988.71 & 2.31 & - & - & 20.00 & 1000.00 \\
\hline \multicolumn{7}{|c|}{ Projectile according to level III threat with $10 \mathrm{~g}$ sabot (40 mm diameter; $19.6 \mathrm{~g}$ weight) } \\
\hline Nitrogen & 493.94 & 1.73 & - & - & 20.00 & 1000.00 \\
\hline Helium & 771.79 & 2.42 & - & - & 20.00 & 1000.00 \\
\hline Hydrogen & 936.31 & 2.79 & - & - & 20.00 & 1000.00 \\
\hline \multicolumn{7}{|c|}{ Projectile according to level III threat with $5 \mathrm{~g}$ sabot ( $40 \mathrm{~mm}$ diameter; $14.6 \mathrm{~g}$ weight) } \\
\hline Nitrogen & 551.01 & 1.85 & - & - & 20.00 & 2500.00 \\
\hline Helium & 901.18 & 2.61 & - & - & 20.00 & 2500.00 \\
\hline Hydrogen & 1133.42 & 3.00 & 1133.42 & - & 20.00 & 2500.00 \\
\hline \multicolumn{7}{|c|}{ Projectile according to level III threat with $10 \mathrm{~g}$ sabot ( $40 \mathrm{~mm}$ diameter; $19.6 \mathrm{~g}$ weight) } \\
\hline Nitrogen & 538.41 & 2.32 & - & - & 20.00 & 2500.00 \\
\hline Helium & 872.19 & 3.15 & 871.79 & - & 20.00 & 2500.00 \\
\hline Hydrogen & 1088.17 & 3.65 & 1082.25 & - & 20.00 & 2500.00 \\
\hline
\end{tabular}

TABLE 5: Achievable muzzle velocities of projectile according to level III threat with $10 \mathrm{~g}$ sabots for different diameters.

\begin{tabular}{|c|c|c|c|c|c|c|}
\hline Gas & $V_{\max }(\mathrm{m} / \mathrm{s})$ & Barrel length $[\mathrm{m}]$ & $V_{3 \mathrm{~m}}[\mathrm{~m} / \mathrm{s}]$ & Sabot diameter $[\mathrm{mm}]$ & Pressure $\left[\mathrm{N} / \mathrm{mm}^{2}\right]$ & Reservoir $\left[\mathrm{cm}^{3}\right]$ \\
\hline \multicolumn{7}{|c|}{ Projectile according to level III threat with different diameter sabot (10 g each, $19.6 \mathrm{~g}$ total weight) } \\
\hline Nitrogen & 538.41 & 2.32 & - & 40.00 & 20.00 & 2500.00 \\
\hline Nitrogen & 550.37 & 2.47 & - & 35.00 & 20.00 & 2500.00 \\
\hline Nitrogen & 549.90 & 3.36 & 549.37 & 30.00 & 20.00 & 2500.00 \\
\hline Nitrogen & 549.56 & 4.92 & 539.48 & 25.00 & 20.00 & 2500.00 \\
\hline Nitrogen & 549.33 & 7.64 & 514.70 & 20.00 & 20.00 & 2500.00 \\
\hline Nitrogen & 549.18 & 13.62 & 469.95 & 15.00 & 20.00 & 2500.00 \\
\hline Nitrogen & 549.08 & 30.63 & 392.62 & 10.00 & 20.00 & 2500.00 \\
\hline Gas & $V_{\max }(\mathrm{m} / \mathrm{s})$ & Barrel length [m] & $V_{3 \mathrm{~m}}[\mathrm{~m} / \mathrm{s}]$ & $V_{6 \mathrm{~m}}[\mathrm{~m} / \mathrm{s}]$ & Pressure $\left[\mathrm{N} / \mathrm{mm}^{2}\right]$ & Reservoir $\left[\mathrm{cm}^{3}\right]$ \\
\hline \multicolumn{7}{|c|}{ Projectile according to level III threat with $10 \mathrm{~g}$ sabot ( $30 \mathrm{~mm}$ diameter; $19.6 \mathrm{~g}$ weight $)$} \\
\hline Nitrogen & 549.90 & 3.36 & 549.37 & - & 20.00 & 2500.00 \\
\hline Helium & 871.04 & 5.65 & 836.01 & - & 20.00 & 2500.00 \\
\hline Hydrogen & 1087.06 & 6.61 & 1013.91 & 1085.78 & 20.00 & 2500.00 \\
\hline \multicolumn{7}{|c|}{ Projectile according to level III threat with $10 \mathrm{~g}$ sabot ( $35 \mathrm{~mm}$ diameter; $19.6 \mathrm{~g}$ weight) } \\
\hline Nitrogen & 550.37 & 2.47 & - & - & 20.00 & 2500.00 \\
\hline Helium & 871.52 & 4.16 & 862.35 & - & 20.00 & 2500.00 \\
\hline Hydrogen & 1087.50 & 4.88 & 1060.50 & - & 20.00 & 2500.00 \\
\hline
\end{tabular}

\section{Conclusions}

Different setups for a one-stage light-gas gun facility have been numerically analyzed in order to evaluate their suitability for usage to test materials and composites for NIJ levels III and IV armor protection. A maximal barrel length of $6 \mathrm{~m}$ and a maximal reservoir pressure of a standard industrial gas bottle $(20 \mathrm{MPa})$ have been chosen as limitations. The numerical predictions show that it is not possible to accelerate the projectile directly to the desired velocity with nitrogen, helium, or hydrogen as propellant gas. When using a sabot corresponding to a higher bore diameter, the necessary velocity is achievable with helium and hydrogen gases. As a next step, a simple and low cost design of a light-gas gun facility might be constructed for impact test of armor protection materials following the indications of this numerical evaluation.

\section{Conflict of Interests}

The authors declare that there is no conflict of interests regarding the publication of this paper. 


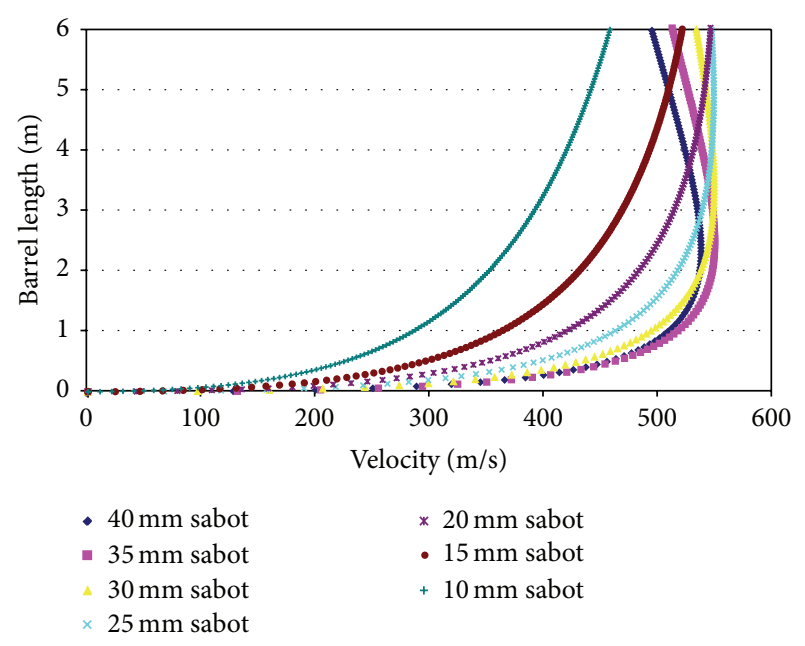

FIGURE 4: Sabot performance: abot/projectile velocity against displacement using nitrogen as driving gas.

\section{Acknowledgments}

The Brazilian funding agencies CAPES and CNPq are gratefully acknowledged.

\section{References}

[1] A. C. Charters, "Development of the high-velocity gas-dynamics gun," International Journal of Impact Engineering, vol. 5, no. 1-4, pp. 181-203, 1987.

[2] C. J. Doolan and R. G. Morgan, "A two-stage free-piston driver," Shock Waves, vol. 9, no. 4, pp. 239-248, 1999.

[3] C. Coolan, A Two-Stage Light Gas Hun for the Study of High Speed Impact in Propellants, DSTO Aeronautical and Maritime Research Laboratory, 2001.

[4] D. Kessler, R. Reynolds, and P. Anz-Meader, Orbital Debris Environment for Spacecraft Designed to Operate in Low Earth Orbit, NASA, 1989.

[5] L. Neckel, D. Hotza, D. Stainer et al., "Solutions for impact over aerospace protection," Key Engineering Materials, vol. 488-489, pp. 25-28, 2012.

[6] United States Department of Justice, Ballistic resistance of body armor, 2006.

[7] D. J. Grosch and J. P. Riegel, "Development and optimization of a "micro" two-stage light-gas gun," International Journal of Impact Engineering, vol. 14, no. 1-4, pp. 315-324, 1993.

[8] N. Thadhani, "High-strain-rate gas-gun laboratory," Georgia Tech, http://www.mse.gatech.edu/research/equipment-facilities/high-strain-rate-gas-gun-laboratory.

[9] A. Stilp, "Hyper velocity impact research," in Proceedings of the 2nd European Conference on Space Debris, 1997.

[10] M. Chavko, W. A. Koller, W. K. Prusaczyk, and R. M. McCarron, "Measurement of blast wave by a miniature fiber optic pressure transducer in the rat brain," Journal of Neuroscience Methods, vol. 159, no. 2, pp. 277-281, 2007.

[11] I. Cernak, "The importance of systemic response in the pathobiology of blast-induced neurotrauma," Frontiers in Neurology, vol. 1, Article ID Aricle 151, pp. 1-9, 2010.
[12] MHI, "Shock tunnel test facility," http://www.mhi-global.com/ products/detail/shock_wind_tunnel.html.

[13] H. Espinosa and S. Nemat-Nasser, "Low-velocity impact testing," in ASM-Handbook, vol. 8, pp. 539-559, 2000.

[14] K. Kondo, O. Fat'yanov, Y. Hironaka, T. Moritoh, and S. Ozaki, "Performance of the three-stage light-gas gun with a preheating stage," in Shock Compression of Condensed Matter, vol. 505 of AIP Conference Proceedings, pp. 1167-1170, 1999.

[15] P. M. Schubel, J.-J. Luo, and I. M. Daniel, "Low velocity impact behavior of composite sandwich panels," Composites Part A: Applied Science and Manufacturing, vol. 36, no. 10, pp. 13891396, 2005.

[16] D. W. Zhou and W. J. Stronge, "Low velocity impact denting of HSSA lightweight sandwich panel," International Journal of Mechanical Sciences, vol. 48, no. 10, pp. 1031-1045, 2006.

[17] D. P. Gonçalves, F. C. L. de Melo, A. N. Klein, and H. A. AlQureshi, "Analysis and investigation of ballistic impact on ceramic/metal composite armour," International Journal of Machine Tools and Manufacture, vol. 44, no. 2-3, pp. 307-316, 2004.

[18] P. Karandikar, G. Evans, S. Wong, M. K. Aghajanian, and M. Sennett, "A review of ceramics for armor applications," Ceramic Engineering and Science Proceedings, vol. 29, no. 6, 2009.

[19] L. Neckel, D. Hotza, D. Stainer, R. Janssen, and H. Al-Qureshi, "Modelling of ballistic impact over a ceramic-metal protection system," Advances in Materials Science and Engineering, vol. 2013, Article ID 698476, 8 pages, 2013.

[20] A. Siegel, The Theory of High Speed Guns, NATO, Brussels, Belgium, 1965.

[21] Y. Porat and M. Gvishi, "The performance of a short-barrelled gas gun," Journal of Physics E: Scientific Instruments, vol. 13, no. 5, pp. 504-505, 1980.

[22] J. R. Brown, P. J. C. Chappell, G. T. Egglestone, and E. P. Gellert, "A gas-gun facility for material impact studies using lowvelocity, low-mass projectiles," Journal of Physics E: Scientific Instruments, vol. 22, no. 9, pp. 771-774, 1989.

[23] I. M. Hutchings and R. E. Winter, "A simple small-bore laboratory gas-gun," Journal of Physics E: Scientific Instruments, vol. 8, no. 2, article 84, 1975.

[24] G. R. Fowles, G. E. Duvall, J. Asay et al., "Gas gun for impact studies," Review of Scientific Instruments, vol. 41, no. 7, pp. 984996, 1970.

[25] T. Børvik, M. Langseth, O. S. Hopperstad, and K. A. Malo, "Ballistic penetration of steel plates," International Journal of Impact Engineering, vol. 22, no. 9-10, pp. 855-886, 1999. 

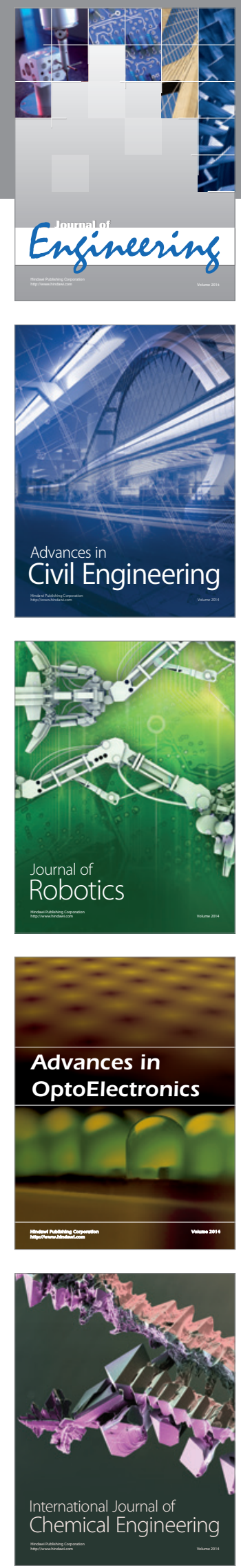

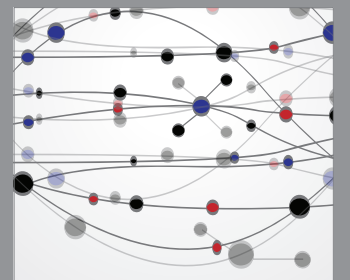

The Scientific World Journal
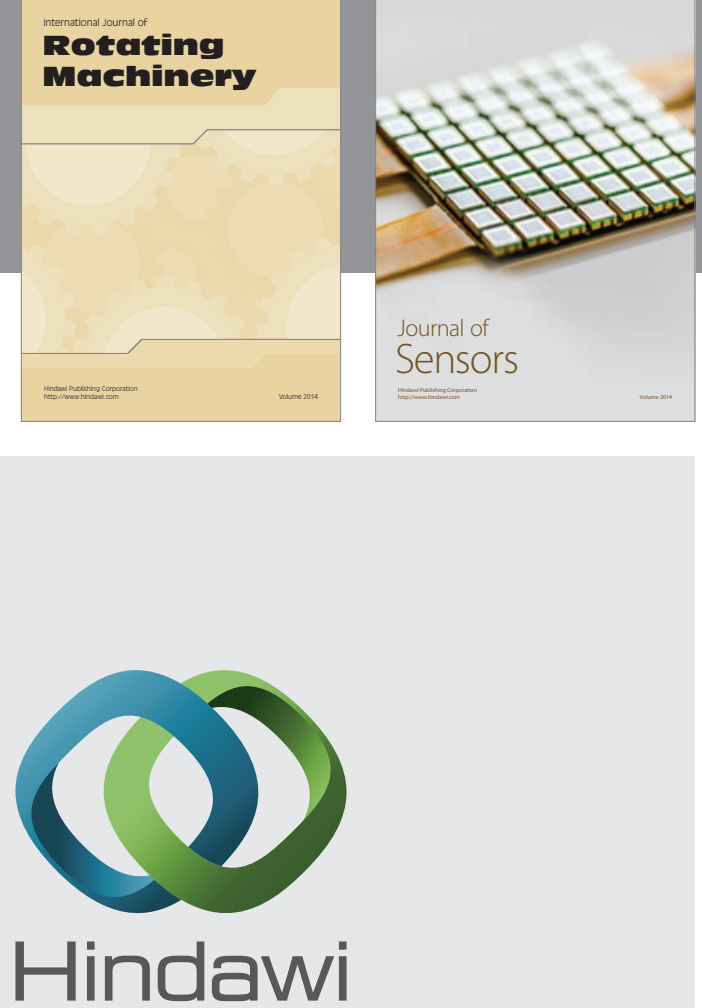

Submit your manuscripts at http://www.hindawi.com
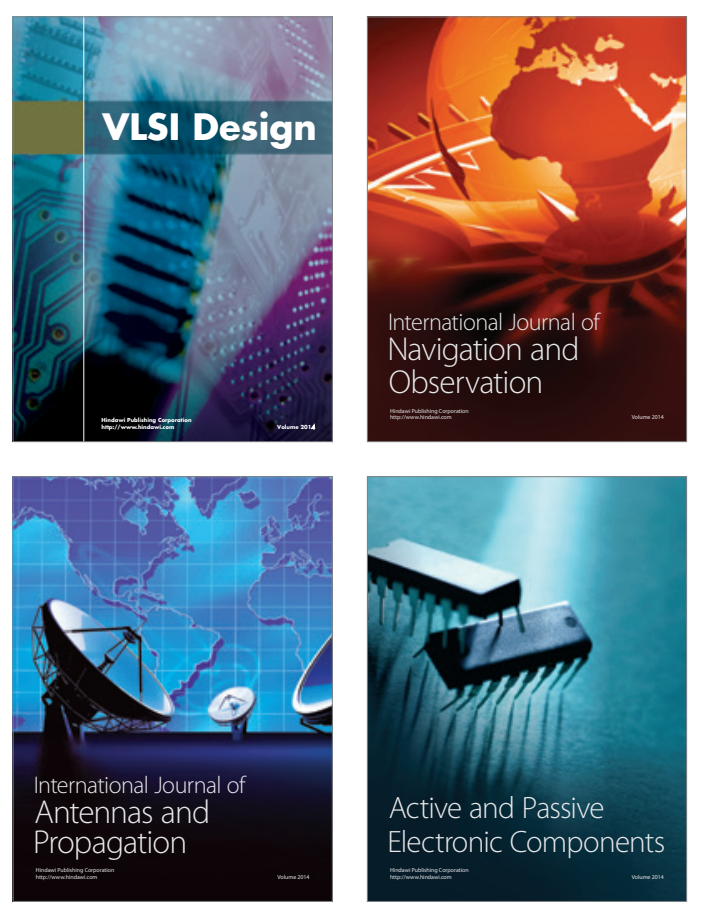
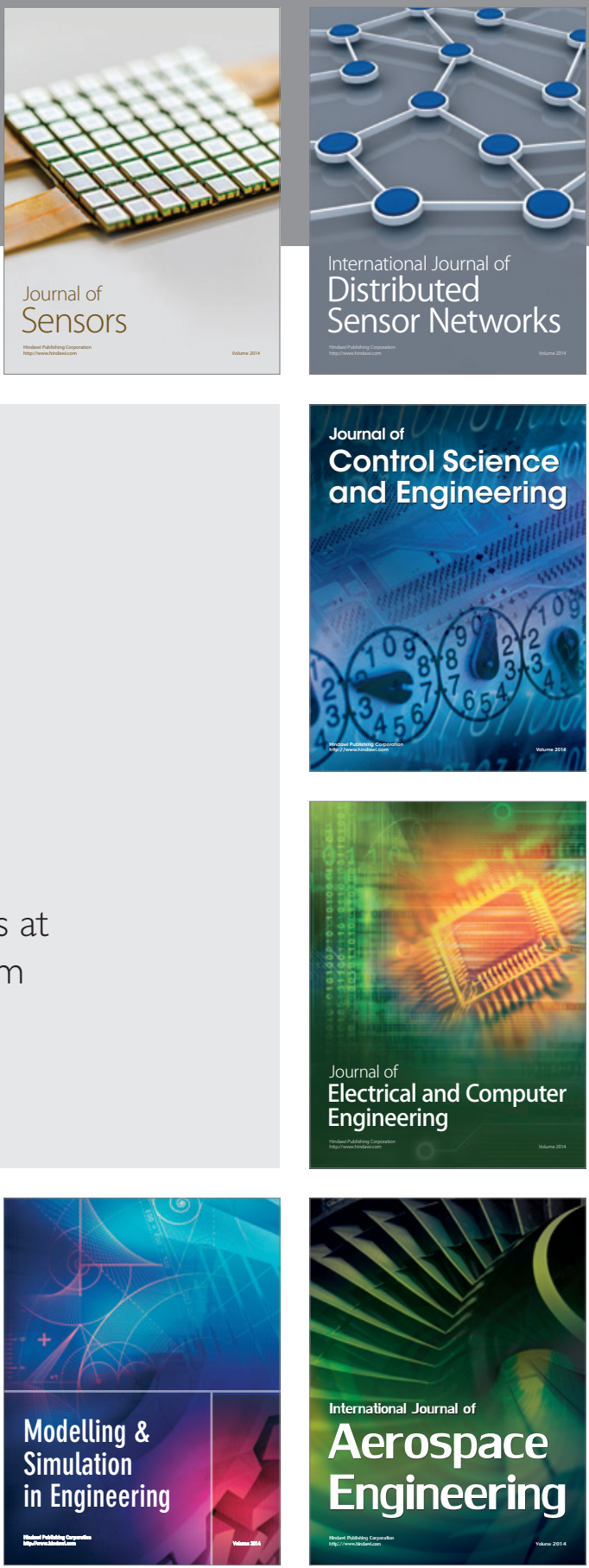

Journal of

Control Science

and Engineering
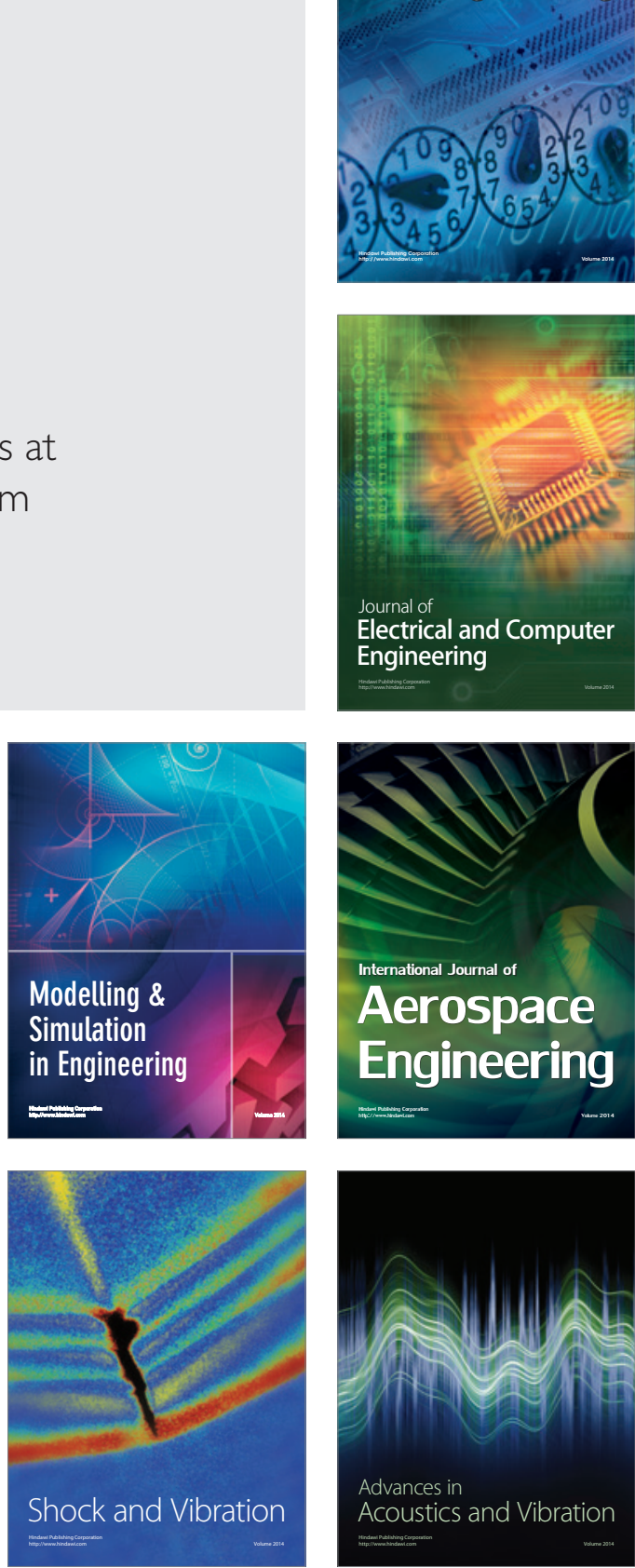